\title{
Study of stability of brown-gray inks on paper support
}

\author{
Milena Reháková ${ }^{*}$, Michal Čeppan $^{1 \dagger}$, Katarína Vizárová ${ }^{1 \dagger}$, András Peller $^{2+}$, Danica Stojkovičová ${ }^{3 \dagger}$ \\ and Monika Hricková ${ }^{1+}$
}

\begin{abstract}
Research into paper artworks and the identification of drawing techniques dating from the 15th to the 19th century from the collection of Slovak National Gallery revealed that the most frequently used means of writing was a set of brown-gray inks. This set includes bistre, sepia, and iron-gall inks (IGI). The light fastness of these organic compounds is not considered very high. Moreover, iron gall inks attack paper support by the processes commonly known as iron gall ink corrosion. In the experimental part of the research, the stability of three different brown-gray inks was studied. Model inks, i.e. bistre, sepia and IGI with two molar ratios Fe : gallic acid were prepared according to historical recipes. Whatman paper was used as a support material. Samples were submitted to accelerated aging in closed vessels at $100^{\circ} \mathrm{C}$ with and without the presence of $\mathrm{NO}_{2}$ in concentration of $100 \mathrm{ppm}$ as well as to the light aging in a light chamber. Changes of mechanical, optical and chemical properties of the samples as well as spectra in the IR region were studied. The observed changes allowed an evaluation of the effect of particular inks on paper support and effect of various external factors of aging (temperature, light, pollutants) on the model systems. Simultaneous thermal analysis (DTA/TG) was carried out in order to study the thermo-oxidative stability of the materials. Sepia and bistre inks have been assessed as generally more stable than iron-gall inks.
\end{abstract}

Keywords: Historical brown-gray inks, Stability of drawings, FT- IR spectroscopy

\section{Background}

Bistre is a brown dye obtained by extraction of soot in boiling water followed by evaporation and drying [1]. Its aqueous suspensions may have a golden-brown, grayish or brown color, depending upon the thickness of the coating. Color is affected by the type of the wood used. The main part of a wood tar composition, which is similar to that of asphalt, is dehydroabietic acid with a lower portion of pyrolytic products [2]. According to other sources [3], the main color components in the bistre ink are formed by substituted, water-soluble phenols. Historical sources refer to the bistre changes of its hue when exposed to light. After being exposed to a strong light source, the tar part oxidizes and the dye gains cooler hue and possibly bleaches [4].

\footnotetext{
* Correspondence: milena.rehakova@stuba.sk

${ }^{\dagger}$ Equal contributors

${ }^{1}$ Slovak University of Technology in Bratislava, Faculty of Chemical and Food Technology, Institute of Natural and Synthetic Polymers, Radlinského 9,

Bratislava, Slovakia

Full list of author information is available at the end of the article
}

Bistre as a writing material was already known in the Middle Ages [5]. In the 15th century, it was widely used in Italy and subsequently in Northern Europe. In the 17th and 18th centuries, the use of bistre was popular among artists such as Rembrandt van Rijn, Claude Lorrain, Conez Alexander and Thomas Gainsborough. Bistre was often used in miniature drawings. Although the inks used by Rembrandt are described traditionally as bistre, analytical studies carried out on 22 Rembrandt drawings from the collection of the Metropolitan Museum of Art have confirmed that the majority of the 22 drawings were made using iron-gall ink [6].

Sepia ink is obtained by adding gum Arabic into the extracts derived from Sepia officinalis cuttlefish. Sepia's main constituents are melanin giving a typical hue of ink and mucous compounds [7]. Grayish brown eumelanin is a macromolecule consisting of 5,6-dihydroxyindol a 5,6-dihydroxyindol-2-karboxylic acid. Melanin significantly absorbs UV and the visible wavelength range and almost all absorbed light energy is converted into the heat [8-11]. Melanin may act as a light stabilizer and this 
fact could explain relatively high light fastness of this organic dye.

Long-term irradiation in the presence of oxygen and UV light, however, results in lightening - the fading of melanin $[12,13]$ that is a result of oxidative degradation, in the process of which the benzene core ring opens [8].

J. Seydelmann was the first person to prepare sepia ink mixed with gum Arabic (as discussed in ref. [14]) as a method of watercolor painting technique in Dresden in 1780. During the 19th century, bistre was gradually substituted by sepia ink.

Main components of iron gall inks (IGI) are hydrolysable extracts from plant materials containing mainly gallotannins and ferrous sulfate [15]. A freshly prepared water solution of ink is a colorless complex of Fe (II) with gallic acid. Writing means gain their typical color by oxidation of Fe (II) into Fe (III) supplying the deep black-blue complex with gallates. With the passage of time, a degradation process of paper support was taking place [16]. This "iron gall inks corrosion" is considered to be directly caused by two particular mechanisms: acid hydrolysis of cellulose (in excess of acidic compound presented in IGI) and the oxidative degradation of paper support catalyzed by the transitional metals (Fe, $\mathrm{Cu}$ ) [17]. After the absorption of light, an excited state of deep-blue complex is created and its reaction with the other ingredients leads to a decomposition into the brown colored compounds [18]. Visual signs of corrosion are brown rims in the ink areas and brown strike through patches of ink appearing on verso.

From the late antique period to the early years of the $20^{\text {th }}$ century, iron gall inks were the most used means of manuscript writing. In $15^{\text {th }}$ century, inks were widely spread and during the following centuries commonly used by the old masters in drawings. At present time, all renowned galleries and museums of the world house the greatest collections of drawings by Leonardo da Vinci, Rembrandt van Rijn, Giovanni Francesco Barbieri known as Guercino, Claude Lorrain, Vincent van Gogh, etc.

The objective of this research was to study the stability of three types of historical brownish gray inks, i.e. bistre, sepia, and iron gall ink on the paper substrate during accelerated thermal aging in dark as well as light aging. This work gives a summary of properties of brown-gray inks based on own survey results. The obtained information can help conservators with an understanding and a broadened knowledge useful in preventive preservation, specifically in determining appropriate storage conditions in depositories and chiefly in expositions. Research into paper artworks of drawing techniques dating from the 15th to the 19th century from the collection of Slovak National Gallery revealed that the using of more kinds of brown-gray inks on one drawing was very frequent [19]. In these cases, the storage conditions must adapt to the most vulnerable ones.

\section{Materials and methods Materials}

Three types of inks were studied: bistre ink 12100 (Kremer Pigmente $\mathrm{GmbH} \& \mathrm{Co} \mathrm{KG}$ ) - B, sepia ink 12401 (Kremer Pigmente GmbH \& Co KG) - $\boldsymbol{S}$, iron gall inks prepared from monohydrate of gallic acid (Sigma Aldrich) and ferrous sulfate heptahydrate (Lachema, Czech Republic). The molar ratios of Fe (II) ion: gallic acid were 1:1 and 1:2 - IGI 11, IGI 12. Solutions of inks were prepared according to Neevel [3]. For their preparation an aqueous (deionized water) solution of gum Arabic (Fluka BioChemika, Sigma-Aldrich) with the mass concentration $7.852 \mathrm{~g} / 100 \mathrm{ml}$ was used. Whatman filter paper (Whatman Lab. Division, Maidstone, England), Cat. No 1001917, 87 g.m ${ }^{-2}$, pH 6.7 - purified cotton linter cellulose was used as a substrate - $\boldsymbol{W}$. Paper samples were immersed into the ink solutions for 15 seconds. Excess liquid was removed using two filter papers and then left to dry at room temperature. Water solutions of iron gall inks were applied to the paper substrate after being kept in dark room for seven days and subsequent filtration.

\section{Methods \\ Accelerated aging methods}

Two methods of accelerated aging were employed. Light aging according to ISO 105-B02 [20]: a laboratory device for simulating daylight consisting of a MeX-lamp OSRAM POWERSTAR HQI TS 400/D UV-reduced and two fluorescent lamps with the maximum of emission spectrum in UVA, power $2 \times 15 \mathrm{~W}$, temperature $45 \pm 5^{\circ} \mathrm{C}$, relative humidity $25 \pm 5 \%$, exposure dose $105 \mathrm{klx}$ in VIS, $95 \mathrm{~mW} / \mathrm{cm}^{2}$ in UVA were used. Exposure times were 20,40, 80, 120 and 160 hours.

Accelerated thermal aging in air with/without pollutant according to ISO 5630-5 [21]: samples were placed in Pyrex ${ }^{\oplus}$ bottles, conditioned for 24 hours at $23^{\circ} \mathrm{C}$ and $50 \% \mathrm{RH}$ and closed with polyphenylsiloxane airtight seal with Viton ${ }^{\bullet}$ gasket. $\mathrm{NO}_{2}$ in a 100 ppm concentration was introduced into selected bottles. Ageing times were 0, 4, $16,24,48,120$ hours for pure paper, bistre and sepia and 1, 2, 4, 8 and 24 hours for iron-gall inks.

\section{Degree of polymerization and the rate constant of depolymerization}

Viscometric measurements were carried out according to ISO 5351-1 [22] using cupriethylene-diamine (CED) as a solvent. Measurements were performed with a standard capillary viscometer at $(25.0 \pm 0.1)^{\circ} \mathrm{C}$. From the ratio $t / t_{0}$, where $t$ is the efflux time of a sample solution and $t_{0}$ is the efflux time of the solvent, the ratio of viscosities of the sample solution and solvent $\eta / \eta_{0}$, and intrinsic viscosity $[\eta]$ was obtained. Degree of polymerization, $D P$, was 
calculated from viscometric data using the MarkHouwink-Sakurada Eq. 1 [7,23,24]:

$$
D P^{a}=K[\eta]
$$

The values of constants $a=0.85$ and $K=1.1$ for cellulose were used [25]. Rate constants $k$ of degradation were obtained by Least Squares Fit of the experimental data using the Ekenstam equation for the degradation of linear polymers $[24,26]$ :

$$
\frac{1}{D P}-\frac{1}{D P_{0}}=k t
$$

where $D P_{0}$ and $D P$ are degrees of polymerization at the beginning of aging and after time of aging $t$.

\section{Folding endurance}

$15 \times 100 \mathrm{~mm}$ samples were air-conditioned (24 hours, $23^{\circ} \mathrm{C}, 50 \% \mathrm{RH}$ ) and folding endurance was measured by the MIT method according to [27]. The device used was Tinius Olsen, tension of samples $3 \mathrm{~N}$, average of 10 measurements, standard deviation $35 \pm 5 \%$.

\section{Thermoanalytical measurements}

Shimadzu DTG-60 simultaneous thermoanalyzer was employed to study the thermal oxidation of the samples. The apparatus involves two thermoanalytical methods, i.e. thermogravimetry (TG) and differential thermal analysis (DTA). The purge gas that was creating the reaction atmosphere was air with a flow rate of $50 \mathrm{ml} / \mathrm{min} .2-3 \mathrm{mg}$ samples with circular shape were cut out using a paper hole punch and were placed in standard aluminium pans; the lids of pans were perforated by 7 pinholes to facilitate the contact of the sample with air. The oxidation was studied under non-isothermal conditions applying linear heating with heating rates of $1,3,5,7,10$ and $15 \mathrm{~K} / \mathrm{min}$. A new predictive method [28] has been suggested based on the fact that the dependence of oxidation onset temperature on heating rate can be plausibly described by the function

$$
T_{\mathrm{i}}=T_{\infty}\left(1-\exp \left[-\beta^{a}\right]\right)
$$

where $T_{\mathrm{i}}$ is the oxidation onset temperature, $\beta$ is the heating rate, $T_{\infty}$ means the isoconversional temperature at an infinite heating rate and $a$ stands for an exponent. Knowing the values of the kinetic parameters $T_{\infty}$ and $a$, the oxidation induction time $\left(t_{\mathrm{i}}\right)$ for a chosen temperature $T$ can be calculated as

$$
t_{\mathrm{i}}(T)=\left(T_{\infty}-T\right) a\left(\ln \frac{T_{\infty}}{T_{\infty}-T}\right)^{\frac{a-1}{a}}
$$

Thermooxidation of both, non-aged and at most aged samples was studied. With regards to thermal ageing, the aging time for the samples $\boldsymbol{W}, \boldsymbol{B}$ and $\boldsymbol{S}$ was 120 hours and for the sample IGI 11, IGI 1224 hours. In the case of light-thermal aging, the aging time was 160 hours for all samples.

\section{Spectroscopic measurements}

FT-IR spectra of samples on paper support were measured with FT-IR spectrophotometer EXCALIBUR series, FTS 3000 MX (Digilab) and FT-IR microscope Varian 610-3R Series by ATR method with diamond crystal. FT-IR spectra of powder dyes were measured in $\mathrm{KBr}$ pellets. Color measurements were done with the SpectroDens A 504009 Premium (Techkon $\mathrm{GmbH}$ ) spectrophotometer, standard illumination D50, standard observer $2^{\circ}$.

\section{Results and discussion}

\section{The evaluation of the optical properties}

During accelerated light and thermal aging (Figure 1), sepia ink was the most stable one, followed by bistre. Both iron gall inks, where the total color difference $\Delta \mathrm{E}_{\mathrm{ab}}^{*}$ reached up to 10-15 (by thermal aging), had the lowest color stability.

Interesting view on the aging provides the graph in the in three-dimensional color space Lab (Figure 2): in the first stage of aging (up to $75 \mathrm{~h}$ ) the value of the lightness $\mathrm{L}^{*}$ decreased, indicating the initial darkening of the ink on the substrate caused by the change of the Fe (II) gallate complex to Fe (III) gallate complex (Eq. 1) [29].

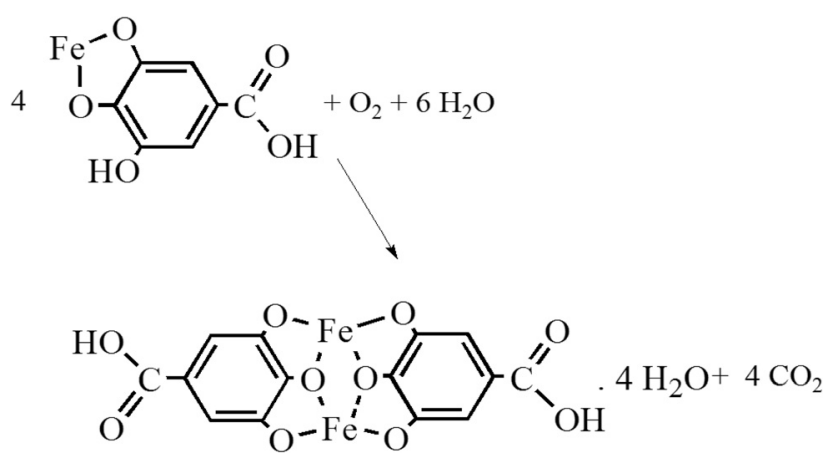

During the further aging, the value of lightness $L^{*}$ increased (ink faded) and the value of chromatic coordinate $b^{*}$ was shifted in yellow direction (changing hue). Color stability assessment of the observed materials can be performed with respect to a set of blue wool standards [20] (BWS). BWS samples underwent accelerated aging under the same conditions as ink model samples. The degree of stability of the studied samples was assessed using the method described by Vizarova et al. [30] Results are summarized in the Table 1. All inks, except bistre, were more stable in light than in thermal 


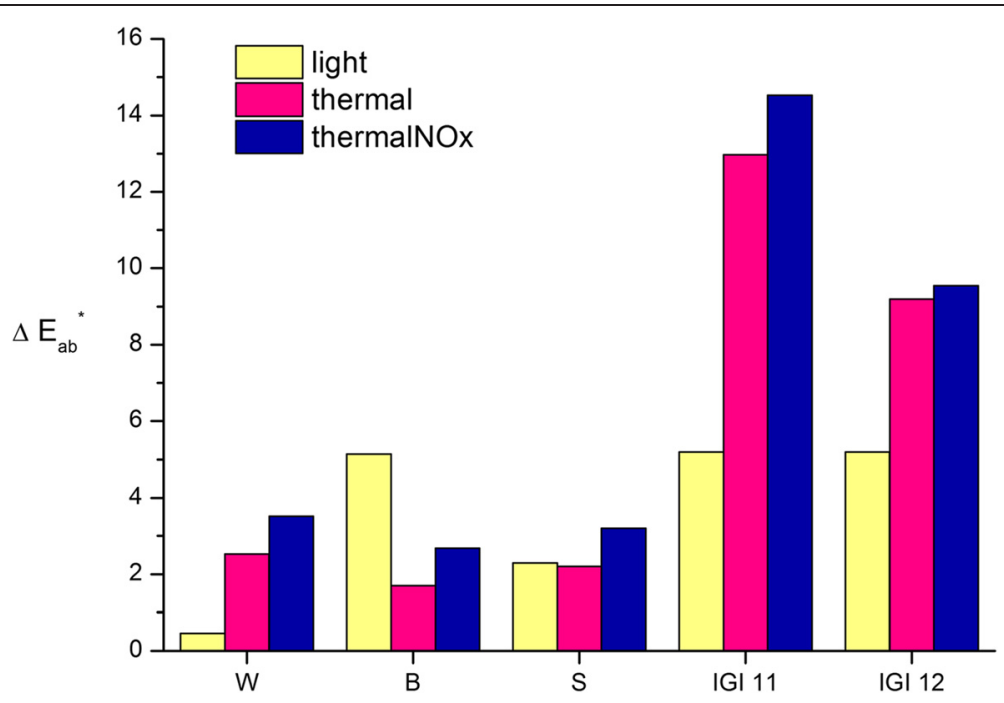

Figure 1 Total color difference of model samples on paper substrate at the maximum time of accelerated light, thermal and thermal aging with presence of $\mathrm{NO}_{2}$.

aging (at the studied aging times). The presence of the $\mathrm{NO}_{2}$ pollutant reduced color stability of all the inks by likely acceleration of oxidation-reduction reactions leading to fading and/or hue changing the present dyes/ pigments.

The evaluation of the mechanical properties

Folding endurance of the papers with sepia and bistre ink was very high during the light aging (Figure 3) (and thermal one, too). These samples showed up to 10 times higher folding endurance compared to the paper pad and decreased only slightly during aging. The presence of a binder (gum Arabic) which provides initial strengthening

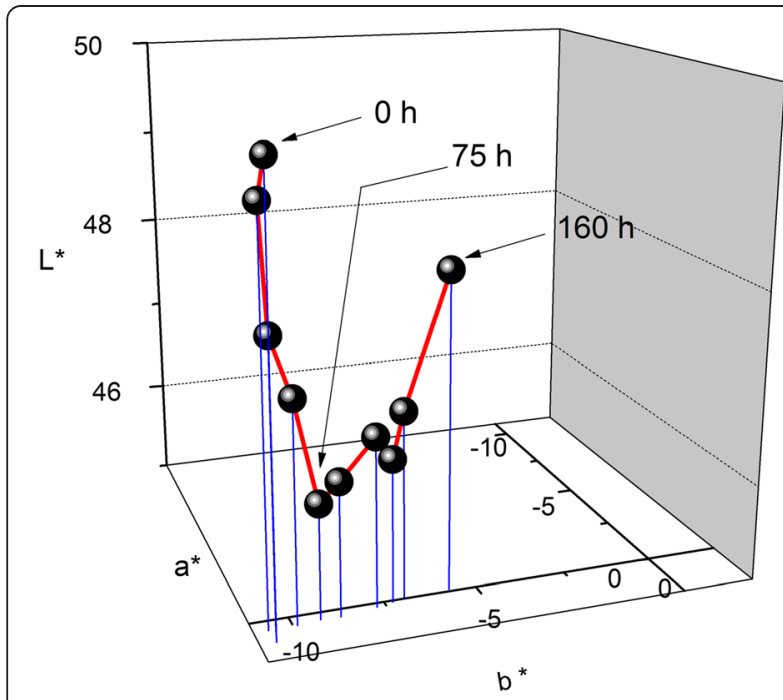

Figure 2 Changes in color coordinates in the color space CIELab during light aging for IGI 11. of paper pad, was the reason of heightened values of folding endurance. The loss of original mechanical properties of IGI's systems was very fast at thermal aging with/without pollutant. Number of double folds of iron gall inks papers decreased to zero already after 24 hours of accelerated aging. It was the evidence of strong attack of iron gall inks oxidation products on paper. These results correspond with results of determination of rate constant of support degradation (below).

\section{Determination of depolymerisation rate constants}

Depolymerisation reactions of cellulose pads during the thermal aging were influenced by the kind of inks and pollutants present. Whatman with sepia degraded relatively slowly, followed by Whatman substrate and Whatman with bistre. Depolymerisation rate constants for the samples with iron gall inks were higher almost by two orders of magnitude (Table 2, bold data). Thermal aging at elevated temperature, relative humidity and the presence of pollutant seems to be very dangerous for the papers containing IGIs via accelerating reactions leading to the reduction of DP.

Table 1 Evaluation of ink's stability considering stability of blue wool standards (minimum 1, maximum 8)

\begin{tabular}{llll}
\hline Sample & \multicolumn{3}{l}{ Degree of stability at the maximal aging time of } \\
\cline { 2 - 4 } & Light aging & Thermal aging & Thermal aging with $\mathrm{NO}_{\mathbf{2}}$ \\
\hline W & 8 & 7 & 6 \\
B & 6 & 7 & 7 \\
S & 7 & 7 & 6 \\
IGI 11 & 6 & 4 & 4 \\
IGI 12 & 6 & 5 & 5 \\
\hline
\end{tabular}




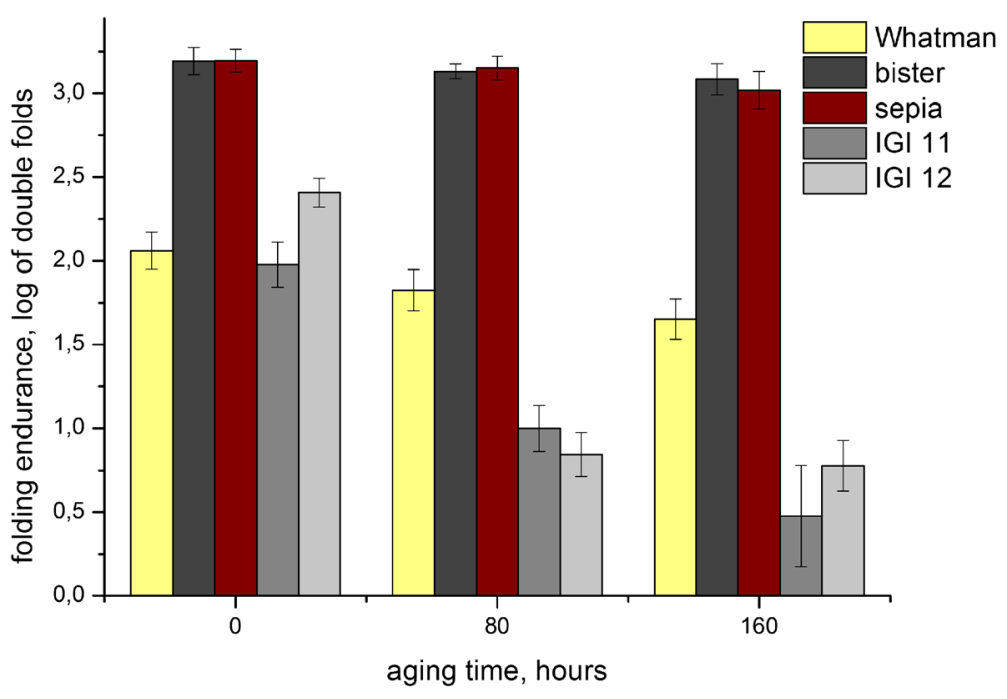

Figure 3 Changes of the folding endurance of model samples on paper at the time of accelerated light aging.

Similar trends were observed for the light aging but the depolymerisation rate constant was of the same order (Table 2).

Degradation of paper pad depended on the ratio of Fe : gallate in the iron gall ink, the most noticeable was at $\mathrm{Fe}: \mathrm{GAL}=1: 1$. This piece of knowledge corresponds with results of optical stability as well (Figure 1, Table 1).

\section{Evaluation of thermooxidation}

The aim of the thermoanalytical methods - thermogravimetry (TG) and differential thermal analysis (DTA) - was to assess the role and proportional representation of depolymerisation and thermooxidation reaction pathways during the aging process. A detailed experimental description and evaluation procedure were published elsewhere [31]. The progress of thermooxidation during accelerated ageing can be characterized by applying the criterion of residual stability [32]. The residual stability of a sample is defined as

Table 2 Values of the depolymerisation rate constants of model samples at the maximum time of light, thermal and thermal aging with $\mathrm{NO}_{2}$

\begin{tabular}{llll}
\hline Sample & \multicolumn{2}{l}{$\begin{array}{l}\text { Depolymerisation rate constant }\left[\mathbf{1 0}^{-\mathbf{6}} \mathbf{s}^{\mathbf{- 1}}\right] \text { at the } \\
\text { maximal aging time of }\end{array}$} \\
\cline { 2 - 4 } & Light ageing & Thermal ageing & $\begin{array}{l}\text { Thermal ageing } \\
\text { with } \mathbf{N O}_{\mathbf{2}}\end{array}$ \\
\hline W & $0.89 \pm 0.10$ & $2.25 \pm 0.26$ & $2.45 \pm 0.23$ \\
B & $1.25 \pm 0.33$ & $1.87 \pm 0.31$ & $2.89 \pm 0.58$ \\
S & $0.72 \pm 0.19$ & $0.81 \pm 0.28$ & $0.88 \pm 0.26$ \\
IGI 11 & $3.09 \pm 0.77$ & $\mathbf{1 0 8 0} \pm \mathbf{2 5 0}$ & $\mathbf{1 5 5 0} \pm \mathbf{2 8 0}$ \\
IGI 12 & $2.24 \pm 0.53$ & $\mathbf{4 9 0} \pm \mathbf{1 0 9}$ & $\mathbf{8 6 0} \pm \mathbf{1 5 0}$ \\
\hline
\end{tabular}

$$
R=\frac{t_{\mathrm{i}}}{t_{\mathrm{i} 0}}
$$

where $t_{\mathrm{i}}$ and $t_{\mathrm{i} 0}$ are the oxidation induction times for the aged and unaged sample, respectively. The oxidation induction times should decrease during accelerated ageing so that the residual stabilities should possess values from the range $\langle 0 ; 1\rangle$; the value 1 corresponds to the unaged sample and the value 0 for the sample exhibiting no stability after the ageing. The residual stabilities of the aged samples are summarized in Table 3. The 95\% reasonability ranges shown also in Table 3 have been obtained as a conjunction of the range $<0 ; 1>$ and the $95 \%$ confidence limits.

The values of $R$ for the Whatman paper after aging can attain any value from the range $<0 ; 1>$ so that no conclusion on the decrease of thermooxidation stability of the sample W during aging can be drawn. A considerable decrease of thermooxidation stability was indicated for the sample IGI 11 after all kinds of aging. The decrease of the thermooxidation stability for bistre does not seem high for all kinds of thermal aging; in the case of light aging, any value from the range $<0 ; 1>$ can be obtained. A surprising result was obtained for the samples with sepia. Within the $95 \%$ confidence interval, the values of $R>1$ for thermal aging and thermal aging with $100 \mathrm{ppm} \mathrm{NO}_{2}$ have been found. This finding can be accounted for in the only way - during thermal aging with and without $\mathrm{NO}_{2}$ a compound preventing thermooxidation was formed.

The results indicate that thermooxidation represents only a minor reaction path in the aging of paper/ brown-gray ink systems during the thermal methods of aging, except for iron-gall inks where the thermooxidation 
Table 3 Estimated residual stabilities $(R)$ with their standard deviations and $95 \%$ reasonability ranges of $R$ at the maximum time of light, thermal and thermal aging with $\mathrm{NO}_{2}$

\begin{tabular}{|c|c|c|c|c|c|c|}
\hline \multirow[t]{3}{*}{ Sample } & \multicolumn{6}{|c|}{ Residual stabilities $(R)$ and $95 \%$ reasonability ranges of $R$} \\
\hline & \multicolumn{2}{|c|}{ Light ageing } & \multicolumn{2}{|c|}{ Thermal ageing } & \multicolumn{2}{|c|}{ Thermal ageing with $\mathrm{NO}_{2}$} \\
\hline & $\mathrm{R}\left(23^{\circ} \mathrm{C}\right)$ & R 95\% & $\mathrm{R}\left(23^{\circ} \mathrm{C}\right)$ & R 95\% & $\mathrm{R}\left(23^{\circ} \mathrm{C}\right)$ & R 95\% \\
\hline W & $0.85 \pm 0.49$ & $0-1$ & $1.8 \pm 1.2$ & $0-1$ & $5.2 \pm 3.4$ & $0-1$ \\
\hline B & $1.7 \pm 0.9$ & $0-1$ & $0.79 \pm 0.19$ & $0.42-1$ & $0.79 \pm 0.23$ & $0.34-1$ \\
\hline $\mathbf{S}$ & $2.4 \pm 2.1$ & $0-1$ & $4.8 \pm 1.6$ & $>1$ & $300 \pm 124$ & $>1$ \\
\hline IGI 11 & $0.49 \pm 0.16$ & $0.18-0.80$ & $0.18 \pm 0.07$ & $0.01-0.71$ & $0.36 \pm 0.18$ & $0.01-0.71$ \\
\hline
\end{tabular}

might become the prevailing degradation reaction path. Moreover, considering the results of rate constants of depolymerisation, the iron-gall inks accelerated both reaction paths, i.e. thermooxidation and depolymerisation. In the case of the light aging, depolymerisation was the prevailing degradation reaction way.

\section{FT-IR spectra}

Changes of FT-IR spectra of aged inks on paper measured by ATR-FT-IR were imperceptible. We therefore decided to study the changes of powder dyes/pigments by transmission technique in $\mathrm{KBr}$ pellets. The most significant changes in the FTIR spectra were observed with IGIs. We found, in particular, a loss of vibration of $\mathrm{SO}_{4}{ }^{2-}$ (1200-970 $\mathrm{cm}^{-1}$ ) [33] from the excess of ferrous sulfate and changes in position of vibration of $-\mathrm{OH}$ and $-\mathrm{C}=\mathrm{O}$ groups at $1700-1600 \mathrm{~cm}^{-1}$ during the thermal aging (Figure 4). We observed conspicuous changes in the vibration range of the chemical bonds of aromatic ring [34] of iron gall inks at $1500-1200 \mathrm{~cm}^{-1}$ during the light aging (Figure 5): shifts of peaks at 1452 to $1426 \mathrm{~cm}^{-1}, 1337$ to $1320 \mathrm{~cm}^{-1}$ and emerging of the new peaks at 1484,1281 a $1268 \mathrm{~cm}^{-1}$. The considerable changes in the FT-IR spectra confirming formation of

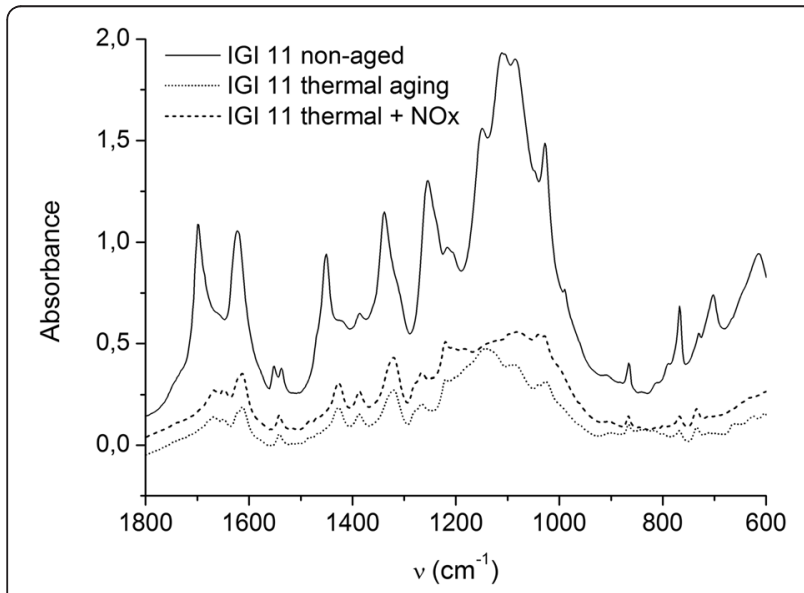

Figure 4 Changes in the part of FT-IR spectra of IGI 11 at the maximum time of accelerated thermal aging. the degradation products of IGIs were related directly to the stage of the cellulose depolymerisation. Changes in FT-IR spectra of bistre and sepia were imperceptible, or none.

\section{Conclusions}

After assessing chemical, optical and mechanical properties of the historic brown-gray ink on the paper support, we concluded that the most stable appears to be the sepia ink, followed by bistre. Iron gall inks are the least stable of all. Degradation of paper pad depends on the ratio of Fe in the iron gall ink, the most noticeable is at Fe: $G A L=1: 1$. The influence of light on stability of brown-gray inks on paper support is less significant than the influence of temperature and pollutants (in the studied time intervals); the most dangerous combination is high temperature with increased relative humidity and presence of air pollutants. Both degradation reaction paths - thermooxidation and depolymerisation in the aging of paper/gray-brown ink systems are noticeable and depend on the way of accelerated aging and the kind of applied ink. The acquired knowledge can be useful for conservators in securing optimum conditions of storage and accessibility of pieces of art.

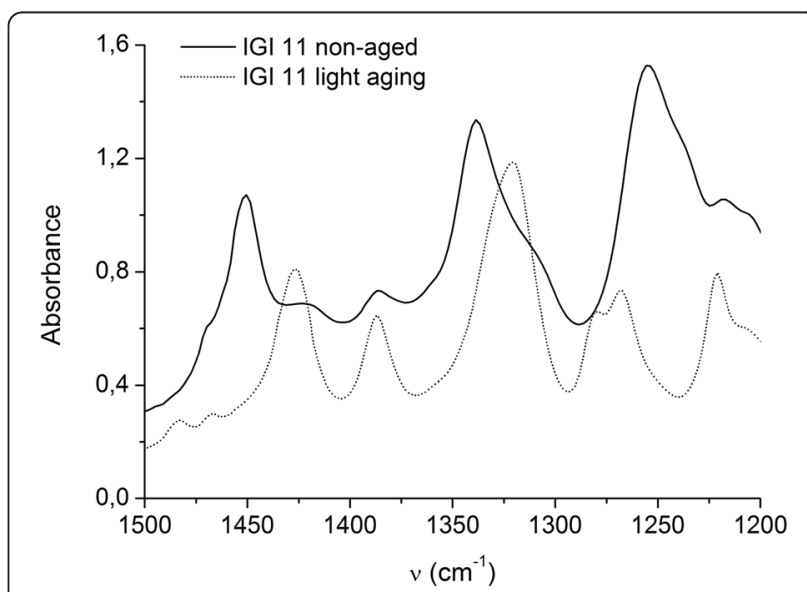

Figure 5 Changes in the part of FT-IR spectra of IGI 11 at the maximum time of accelerated light aging. 


\section{Competing interests}

The authors declare that they have no competing interests.

\section{Authors' contributions}

MR conceived the study and made substantial contributions to conception and design. MC managed the research in the field of historical brown-gray inks and contributed to their identification. KV made data acquisition and interpretation. AP performed analysis of thermooxidative stability. $\mathrm{MH}$ performed the field work. DS participated in coordination and helped to draft the manuscript. All authors read and approved the final manuscript.

\section{Acknowledgements}

This work was accomplished under the auspices of the Slovak Research and Development Agency under the contract No. APW-0324-10.

\section{Author details}

1Slovak University of Technology in Bratislava, Faculty of Chemical and Food Technology, Institute of Natural and Synthetic Polymers, Radlinského 9, Bratislava, Slovakia. ${ }^{2}$ Slovak University of Technology in Bratislava, Faculty of Chemical and Food Technology, Institute of Organic Chemistry, Catalysis and Petrochemistry, Radlinského 9, Bratislava, Slovakia. ${ }^{3}$ Department of Art Conservation and Restoration, Academy of Fine Arts, Drotárska 44, Bratislava, Slovakia.

\section{Received: 26 September 2014 Accepted: 10 February 2015}

Published online: 01 April 2015

\section{References}

1. Watrous J. The craft of old-master drawings. Madison: The University of Wisconsin Press; 1957.

2. Winter J, FitzHugh WE. Pigments based on carbon. In: Berrie HB, editor Artists' Pigments. London: Archetype; 2007. p. 1-37.

3. Neevel JG. The develpoment of in-situ methods for identification of iron gal inks. In: Kolar J, Strlič M, editors. Iron gall inks: on manufacture, characterisation, degradation and stabilisation. Ljubljana, Slovenia: National and University Library; 2006. p. 147-72.

4. Church $\mathrm{AH}$. The chemistry of paints and painting. 4th ed. Seeley: Service \& Co. Ltd., London; 1915

5. Le Bégue J. Experimenta de coloribus. In: Merrifield MP, editor. The original treatises. London 1847: Dover Publ. New York; 1966.

6. Shelley M. Rembrandt's inks. In: Jensen CW, editor. The Book and Paper Group Annual, The American Institute for Conservation. 2nd ed. 1983.

7. Lopez-Montez A, Blanc R. Characterization of sepia ink in ancient graphic documents by capillary electrophoresis. Microchem J. 2009:93:121-6.

8. Meredith P, Sarna T. The physical and chemical properties of eumelanin. Pigment Cell Res. 2006;19:572-94.

9. Sarna T. Properties and function of the ocular melanin - a photophysical view. J Photochem Photobiol B. 1992;12:125-58.

10. Sarna T, Swartz HM. Interaction of melanin with oxygen (and related species). In: Scott G, editor. Atmosheric Oxidation and Antioxidants, vol. III. Amsterdam: Elsevier; 1993.

11. Meredith P, Powell BJ, Riesz J, Nighswander-Rempel SP, Pederson MR, Moore EG. Towards structure-property-function relationship for eumelanin. Soft Mater. 2006;2:37-44.

12. Chedelek MR, Smith SK, Post PW, Pokora A, Vessell DL. Photodestruction of pheomelanin: role of oxygen. Proc Natl Acad Sci U S A. 1993;75:5395-9.

13. Zreba M, Sarna T. Effects of photodegradation on the physical and antioxidant properties of melanosomes isolated from retinal pigment epithelium. Photochem Photobiol. 2006:82:1024-9.

14. Hebenstreit W. Wissenschaftlich-literarische Enzyklopädie der Aesthetik. Strauss and Cramer GmbH (Ed.), Wien, Gerold; 1843. LXXXVII, 994 p.

15. Mitchell CA, Hepworth TC. Inks - their composition and manufacture. 2nd ed. London: Ch. Griffin \& Cy., Ltd.; 1916.

16. Reissland B. Ink corrosion aqueous and non-aqueous treatment of paper objects - state of the art. Restaurator. 1999;20:167-80.

17. Kolar J, Strlič M. Evaluating the effects of treatments on iron gall ink corroded documents. A new analytical methodology. Restaurator. 2004:25:94-103.

18. Popoff T, Theander O. Formation of aromatic compounds from carbohydrates. IV. Chromones from reaction of hexuronic acids in slightly acidic aqueous solution. Acta Chem Scand. 1976;B30:705-10.
19. Gál L, Čeppan M, Reháková M, Dvonka V, Tarajčáková J, Hanus J. Chemometric tool for identification of iron-gall inks by use of visible-near infrared fibre optic reflection Spectroscopy. Anal Bioanal Chem. 2013:405:9085-91.

20. ISO. Textiles - tests for colour fastness - part B02. In: Colour fastness to artificial light: xenon arc fading lamp test. Geneva: International Organization for Standardization; 1988. ISO 105-B02.

21. ISO. Paper and board - accelerated ageing - part 5. In: Exposure to elevated temperature at $100^{\circ} \mathrm{C}$. Geneva: International Organization for Standardization; 2008. p. 5630-5. ISO.

22. ISO. Cellulose in dilute solutions - determination of limiting viscosity number - Part 1. In: Method in cupriethylene-diamine (CED) solution. Geneva: International Organization for Standardization; 1981. p. 5351-1. ISO.

23. Strlič M, Kolar J, Žigon M, Pihlar B. Evaluationof size-exclusion chromatography and viscometry for the determination of molecular masses of oxidised cellulose. J Chrom A. 1998;805:93-9.

24. Emsley AM, Heywood RJ, Ali M, Eley CM. On the kinetics of degradation of cellulose. Cellulose. 1997:4:1-5.

25. Evans R, Wallis AFA. Comparison of cellulose molecular weight determined by HPSEC and viscometry. In: Proceedings of the 4th International symposium on wood, fibre and pulping chemistry. Paris, France: Eucepa; 1987. p. 201-5.

26. Kolar J, Štolfa A, Strlič M, Pompe M, Pihlar B, Budnar M, et al. Historical iron gall ink containing documents - properties affecting their condition. Anal Chim Acta. 2006;555:167-74.

27. ASTM International. Standard test method for folding endurance of paper by the M.I.T. tester. Conshohocken, Pennsylvania 19428, USA: ASTM International; 2007. ASTM D2176-97a.

28. Šimon P. Material stability predictions applying a new non-Arrhenian temperature function. J Therm Anal Cal. 2009;97:391-6.

29. Hynes MJ, Coinceanainn MO. The kinetics and mechanism of the reaction of iron (III) with gallic acid, gallic acid methyl ester and catechin. J Inorg Biochem. 2001;85:131-42.

30. Vizarova K, Rehakova M, Kirschnerova S, Peller A, Šimon P, Mikulašik R. Stability studies of materials applied in the restoration of a baroque oil painting. J Cult Her. 2011;12:190-5.

31. Peller A, Reháková M, Ciglanská M, Šimon P. Role of thermoxidation and depolymerization in the aging of systems paper/gum arabic/historical ink. Chem Pap. 2014;68:564-74.

32. Fratričová $M$, Šimon $P$, Schwarzer $P$, Wilde H-W. Residual stability of polyurethane automotive coatings measured by chemiluminescence and equivalence of Xenotest and Solisi ageing tests. Polym Degrad Stab. 2006;91:94-100.

33. Senvaitiene J, Beganskiene A, Kareiva A. Spectroscopic evaluation and characterization of different historical writing inks. Vibrational Spectroscopy. 2005:37:61-7.

34. Hamilton GA. Role of oxygen radicals in biological systems. In: Hayashi O, editor. Molecular mechanism of oxygen activation. New York: Academic Press; 1974. p. 405-51.

Publish with ChemistryCentral and every
scientist can read your work free of charge
"Open access provides opportunities to our
colleagues in other parts of the globe, by allowing
anyone to view the content free of charge."
W. Jeffery Hurst, The Hershey Company.
- available free of charge to the entire scientific community
- peer reviewed and published immediately upon acceptance
- cited in PubMed and archived on PubMed Central
- yours - you keep the copyright
Submit your manuscript here:
htpp://www.chemistrycentral.com/manuscript/

